\title{
An assessment of empathy levels of dental students' in Nepal: A cross-sectional comparative study
}

\section{Ghimire S', Dixit PB², Roy DK ${ }^{3}$, Dhital S ${ }^{4}$, Dahal S $^{5}$}

'Siddharth Ghimire, Lecturer; ${ }^{2}$ Punam Basnet Dixit, Associate Professor; ${ }^{3}$ Deepak Kumar Roy, Lecturer, Department of Conservative Dentistry and Endodontics; ${ }^{4}$ Shweta Dhital, Lecturer, Department of Pedodontics and Preventive Dentistry; ${ }^{5}$ Sirjana Dahal, Lecturer, Department of Community and Public Health Dentistry, Kathmandu Medical College Teaching Hospital, Duwakot, Bhaktapur, Nepal.

\begin{abstract}
Background: Empathy is a behavioural aspect of understanding and communicating with a desire to help. Empathy in medical personnel with patient is one of the basic ingredients of good physician/dentist -patient relationships.

Objectives: To assess empathy level among dental undergraduate students, interns and dental postgraduate students of Nepal and to investigate the differences in empathy scores based on gender and year of dental training.

Methodology: A cross-sectional questionnaire study was carried out among 240 dental students of different dental colleges in Nepal. Eighty students were included in each group of third to final-year undergraduate dental students, interns and postgraduate students. Data was collected using a standard-validated, self-administered Jefferson Scale of Empathy-Health Care Provider Student Version (JSE-HPS). This questionnaire included 20 items with a seven-point Likert scale. This scale has relevant content that allows assessing empathy between students and their patients. The collected data was entered in Microsoft Excel and statistical analysis was done in Statistical Package for the Social Sciences version 20.

Results: Out of 240 dental students, 74 (30.8\%) were males and 166 (69.2\%) were females with the mean age of $25.35 \pm$ 3.203. The mean empathy score was $79.59 \pm 6.492$. There was no significant difference in mean empathy level score by gender. The interns were the most empathetic $(80.80 \pm 6.147)$. The mean empathy score was found to be highest for the students with less than one year of experience of treating patient $(81.85 \pm 7.841)$.

Conclusion: Empathy should be given importance to in dental curriculum to improve dentist-patient relationship, thereby improving the treatment outcomes.
\end{abstract}

Key words: Dental students; Dentist-patient relationship; Empathy.

DOI: https://doi.org/10.3126/jkmc.v8i3.29720

\section{INTRODUCTION}

mpathy is one of the basic "elements" of a good

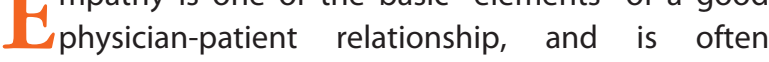
considered an important attribute for professionals in

\section{Address for correspondence}

\section{Dr. Siddharth Ghimire}

Lecturer, Department of Conservative Dentistry and Endodontics Kathmandu Medical College Teaching Hospital

Duwakot, Bhaktapur, Nepal

E-mail: drsiddharthghimire@gmail.com

ORCID: https://orcid.org/0000-0003-2687-7209

ORCID: Punam Basnet Dixit: https://orcid.org/0000-0001-7745-1318 Deepak Kumar Roy: https://orcid.org/0000-0001-5057-7922 Shweta Dhital: https://orcid.org/0000-0002-7786-9869 Sirjana Dahal: https://orcid.org/0000-0002-0536-1230 health care ${ }^{1}$. Empathy was first introduced in the context of patient care by Hojat (2007), as a predominantly cognitive (rather than emotional) attribute that involves an understanding (rather than feeling) of experiences, concerns and perspectives of the patients, combined with a capacity to communicate this understanding ${ }^{2}$. Pedersen (2009) explains empathy as 'appropriate understanding of the patient ${ }^{\prime 3}$. Both empathy and sympathy involves sharing but the concept of empathy lies in cognitive understanding whereas sympathy involves sharing emotions with the patients ${ }^{1}$.

Empathy in the healthcare setting can be best viewed as a cognitive and behavioral attribute that involves the ability to understand how a patient's experiences their feeling which are influenced by their symptoms, illness 
and the capability to communicate this understanding to the patient ${ }^{4}$. To be empathetic, a caregiver must have both the capacity and desire to "take a walk in another's shoes" and the ability to communicate with the "owner of the shoes"

Demonstration of empathy by dentists has been correlated with decreased dental fear, increased compliance with orthodontic treatment, improved treatment success and cooperation in pediatric patients, improved treatment outcomes in myofacial pain, and increased patient satisfaction ${ }^{6}$. But the role of empathy in the dentist-patient relationship has received less attention ${ }^{1,4,6}$. Hence, the present study was conducted to assess empathy level among dental undergraduate students, interns and postgraduate students of different dental colleges in Nepal and to investigate the differences in empathy scores based on gender and year of dental training.

\section{METHODOLOGY}

This is a cross-sectional questionnaire study carried out from February 2019 to May 2019 among third to final-year undergraduate dental students, interns and postgraduate students of Nepal.

Ethical clearance was obtained from the Institutional Review Committee of Kathmandu Medical College (Ref no. 080820113). Students aged 16 and above willing to participate were included in the study. Students under the influence of drugs and psychiatric medication were excluded from the study.

Sample size was calculated as 240 using data of similar study ${ }^{7}$. Eighty students were included in each group of third to final-year undergraduate dental students, interns and postgraduate students. There are 12 dental colleges in Nepal. Among them, six dental colleges were selected by random sampling method and from those six colleges, students were selected randomly by population proportion method.

Data was collected using a validated, self-administered Jefferson Scale of Empathy-Health Care Provider Student Version (JSE-HPS). This questionnaire included 20 items answered on a seven-point Likert scale, which had relevant content that allows assessing empathy between students and their patients. The Jefferson Scale of Empathy - Health Care Provider Student Version scores can range from a minimum of 20 to a maximum of 140 with the level of empathy increasing with an increase in the scores obtained.

Pre-testing of the questionnaire was done among $10 \%$ of the total sample size before the start of study in similar subject group. Response of the pre-tested subject were analyzed for reliability of the questionnaire. Those students involved in pre-testing were not included among the final sample.

The collected data was entered in Microsoft Excel and statistical analysis was done in Statistical Package for the Social Sciences version 20. The descriptive statistics analysis was done using mean, median, mode and range. The inferential statistics was done using chi-square test for categorical data, one way ANOVA and independent t-test for quantitative data.

\section{RESULTS}

A total of 240 dental students participated in the study with a mean age of $25.35 \pm 3.203$. Out of $240(100 \%)$ dental students, 74 (30.8\%) were males and 166(69.2\%) were females. Eighty students were included in each group of third to final-year undergraduate dental students, interns and postgraduate students. The mean empathy score was $79.59 \pm 6.492$.The mean empathy level score was more in males $(80.03 \pm 7.203)$ than females $(79.39 \pm 6.162)$. However, the difference was not statistically significant ( $p=0.485$ ). The mean empathy score was found to be highest for the interns $(80.80 \pm 6.147)$ followed by undergraduates (79.78 \pm $6.793)$ and postgraduates $(78.19 \pm 6.331)$ (Table 1). The difference in the mean empathy score across the year of study was statistically significant $(p=0.037)$. On further comparison, significant mean difference was seen between undergraduate and postgraduate students $(p=0.014)$ (Table 2).

The mean empathy score was found to be highest for the students with less than one year of experience of treating patients(81.85 \pm 7.841$)$ followed by students with experience of treating patients fora period of one year to 4.9 years(79.54 \pm 5.979$)$ and students with experience of treating patients for five years and above (78.21 \pm 6.297).

On further comparison, significant difference was seen between those with experience of less than one year and those with five years and more $(p=0.019)$ (Table 3$)$. 
Table 1: Mean empathy scores of respondents by gender, age, years of study and years of treating patients

\begin{tabular}{|c|c|c|c|}
\hline Factors & n (\%) & Mean \pm SD & p-value \\
\hline \multicolumn{4}{|l|}{ Gender } \\
\hline Male & $74(30.8 \%)$ & & \multirow{2}{*}{$0.485^{*}$} \\
\hline Female & $166(69.2 \%)$ & & \\
\hline Age (years), mean age $\pm S D$ & & $25.35 \pm 3.203$ & \\
\hline \multicolumn{4}{|l|}{ Years of study } \\
\hline Undergraduates & $80(33.33 \%)$ & $79.78 \pm 6.793$ & \multirow[b]{3}{*}{$0.037 \#$} \\
\hline Interns & 80 (33.33\%) & $80.80 \pm 6.147$ & \\
\hline Postgraduates & $80(33.33 \%)$ & $78.19 \pm 6.331$ & \\
\hline Total & $240(100 \%)$ & $79.59 \pm 6.492$ & \\
\hline \multicolumn{4}{|l|}{ Years of treating patients } \\
\hline$<1$ year & $41(17.08 \%)$ & $81.85 \pm 7.841$ & \multirow{3}{*}{$0.019 \#$} \\
\hline $1-4.9$ years & $136(56.67 \%)$ & $79.54 \pm 5.979$ & \\
\hline$\geq 5$ years & $63(26.25 \%)$ & $78.21 \pm 6.297$ & \\
\hline Total & $240(100 \%)$ & $79.59 \pm 6.492$ & \\
\hline
\end{tabular}

* Independent t-test

\# One way ANOVA

Table 2: Comparison of mean empathy scores based on the year of study (Level)

\begin{tabular}{|c|c|c|c|c|c|c|}
\hline \multirow[b]{2}{*}{ Year of study(Level) } & \multirow[b]{2}{*}{ Year of study(Level) } & \multirow{2}{*}{$\begin{array}{c}\text { Mean } \\
\text { Difference }\end{array}$} & \multirow[b]{2}{*}{ Std. Error } & \multirow[b]{2}{*}{ p-value \# } & \multicolumn{2}{|c|}{ 95\% Confidence Interval } \\
\hline & & & & & $\begin{array}{l}\text { Lower } \\
\text { Bound }\end{array}$ & Upper Bound \\
\hline \multirow{2}{*}{ Undergraduates } & Interns & -1.025 & 1.017 & 0.572 & -3.42 & 1.37 \\
\hline & Postgraduates & 1.588 & 1.017 & 0.264 & -0.81 & 3.99 \\
\hline \multirow{2}{*}{ Interns } & Undergraduates & 1.025 & 1.017 & 0.572 & -1.37 & 3.42 \\
\hline & Postgraduates & $2.612^{*}$ & 1.017 & 0.029 & -0.21 & 5.01 \\
\hline \multirow{2}{*}{ Postgraduates } & Undergraduates & -1.588 & 1.017 & 0.264 & -3.99 & 0.81 \\
\hline & Interns & $-2.612^{*}$ & 1.017 & 0.029 & -5.01 & -0.21 \\
\hline
\end{tabular}

* The mean difference is significant at the 0.05 level.

\# Post hoc test

Table 3: Comparison of mean empathy scores based on the years of treating patients

\begin{tabular}{|c|c|c|c|c|c|c|}
\hline \multirow{2}{*}{$\begin{array}{c}\text { Years of treating } \\
\text { patients }\end{array}$} & \multirow{2}{*}{$\begin{array}{c}\text { Years of treating } \\
\text { patients }\end{array}$} & \multirow{2}{*}{$\begin{array}{c}\text { Mean } \\
\text { Difference }\end{array}$} & \multirow[b]{2}{*}{ Std. Error } & \multirow[b]{2}{*}{ p-value \# } & \multicolumn{2}{|c|}{ 95\% Confidence Interval } \\
\hline & & & & & Lower Bound & Upper Bound \\
\hline \multirow{2}{*}{$<1$ year } & $1-4.9$ years & 2.310 & 1.142 & 0.109 & -0.38 & 5.00 \\
\hline & $\geq 5$ years & 3.647 & 1.287 & $0.014^{*}$ & 0.61 & 6.68 \\
\hline \multirow{2}{*}{$1-4.9$ years } & $<1$ year & -2.310 & 1.142 & 0.109 & -5.00 & 0.38 \\
\hline & $\geq 5$ years & 1.338 & 0.977 & 0.359 & -0.97 & 3.64 \\
\hline \multirow{2}{*}{$\geq 5$ years } & $<1$ year & -3.647 & 1.287 & $0.014^{*}$ & -6.68 & -0.61 \\
\hline & $1-4.9$ years & -1.338 & -0.977 & 0.359 & -3.64 & 0.97 \\
\hline
\end{tabular}

* The mean difference is significant at the 0.05 level.

\# Post hoc test 


\section{DISCUSSION}

In the present study, an attempt is made to assess empathy levels among clinical undergraduate students $\left(3^{\text {rd }}, 4^{\text {th }}, 5^{\text {th }}\right.$ year and interns) and postgraduate students attached to dental colleges of Nepal as these students interact with patients in clinical postings.

The total mean empathy score in the present study was $79.59 \pm 6.793$ which was comparatively higher than in other studies ${ }^{8,9}$ and in contrast to some studies ${ }^{1,10,11}$ which reported more empathy levels among dental students compared to this study. This difference in empathy level could be a result of different cultural values, religious beliefs or traditions. It has been reported earlier that cultural differences, ethnicity, religious beliefs, and sex stereotyping may lead to empathy score disparity and can also influence empathic engagement during clinical encounters ${ }^{6}$.

Although the mean empathy level score was more in males than females the difference was not statistically significant ( $p=0.485$ ) which was similar to other studies $^{5,8,11}$. In contrast, some studies ${ }^{9,12}$ showed that male students had a comparatively higher empathy score than female dental students whereas other studies $^{4,7,13}$ reported that females score higher than males. Empathy is a natural human emotion; gender differences may be due to their genetic differences and differences in socialization, and empathy is merely based on motivation rather than capability ${ }^{12}$.

The mean empathy score was found to be highest for the interns followed by undergraduates and postgraduates which is similar to some studies ${ }^{11}$ contrastingto some studies $^{7,9,12}$. The higher score in interns is attributed to the responsibilities given to the interns towards patient care and their urge to start their clinical practice which

\section{REFERENCES}

1. Babar MG, Omar H, Lim LP. An assessment of dental students'empathy levels in Malaysia. Int J Med Educ. 2013; 4:223-9.[DOI]

2. Hojat M. Empathy in Patient Care: Antecedents Development, Measurement, and Outcomes. NewYork, NY: Springer; 2007.[FullText]

3. Pedersen R. Empirical research on empathy in medicine- a critical review. Patient EducCouns. 2009; 76:307-22. [DOI]

4. Sherman JJ, Cramer A. Measurement of changes in empathy during dental school. J Dent Educ. 2005;69:338-45.[PubMed] makes them "Standing in patients'shoes" a necessity for successful dental practice ${ }^{6}$.

Regarding postgraduates, lowest score in empathy level may be due to the fact that during the initiation of the dental course, students believe in idealism, i.e., sharing the feeling of the patients but with the progression of the dental course these feelings vanish, i.e., idealism gives way to the realization (means to get through the various level of dental degree meritoriously, requisite is to acquire enormous dimensions of facts) ${ }^{7}$. Hence, significant perspectives such as sharing the thoughts and feelings of the patients are put aside and emphasis swings on facts-based examinations.

In the present study, mean empathy score was found to be highest for the interns followed by undergraduates and postgraduates. It is very important to introduce exercise regarding empathy among dental students at the initiation of and during their dental course.

\section{CONCLUSION}

The mean empathy level of students who participated in this study was much lower to the average empathy level reported by previous studies. There was no significant gender difference in mean empathy levels. Interns were most empathetic followed by undergraduate and postgraduate students.The empathy score among all students was found to be highest among interns followed by undergraduates and low level of empathy was seen among postgraduate students. As this study was cross-sectional in design it did not allow a baseline assessment or tracking changes in empathy level across the year levels of program. Hence, further studies, preferably longitudinal in design should help explore changes in empathy level in dental students.

5. Hoskin E, WoodmanseyK, Beck L, Rodriguez T. Dental Students' Perceptions of Dentist-Patient Interactions: An Exploration of Empathy in Dental Students. Strides Dev Med Educ. 2018; 15(1): e65124.[DOI]

6. Prabhu S, Kumar VS, Prasanth SS, Kishore S. Standing in patients' shoes - survey on empathy among dental students in India. J Educ Ethics Dent. 2014; 4:69-73[FullText]

7. Aggarwal VP, Garg R, Goyal N, Kaur P, Singhal $S$, Singla N, et al. Exploring the missing link Empathy among dental students: An institutional cross-sectional survey. Dent Res J.2016;13:419-23. [DOI] 
8. Beattie A, Durham J, Harvey J, Steele J, McHanwell S. Does empathy change in first-year dental students? Eur J Dent Educ. 2012;16: e111-e6.[DOI]

9. Datta G, Vanishree N, Nayak SS, Bullappa D, Naveen N, Lakshmikantha R, Prasad KS, Anushri M. Measuring Empathy Towards Patients among Dental Under Graduate Students of Bangalore City-A Cross Sectional Study. J Med Public Health. 2016; 6(3):113-6.[FullText]

10. Jabarifar SE, Khalifesoltani FS, Nilchian F, Yousefi A, Hoseinpour K. Empathy levels in undergraduate and postgraduate dental students in Isfahan Faculty of Dentistry in 2011.Journal of Isfahan Dental School. 2012; 7(5):753-62.[FullText]
11. Kumar PR, Dave PH,Thenmozhi S. Empathy levels among dental students in India. International Journal of Current Research. 2016;8(06):33418-20. [FullText]

12. Kalyan SV, Manjula S, Padma TM, PratapKV, Vineela $P$, Varma SC. Assessment of empathy among clinical dental students in a teaching dental institution in Telangana State, India. J Indian AssocPublic Health Dent. 2017;15:162-5.[DOI]

13. Torres-Martínez PA, Barrios-Penna CA, FonsecaMolina JF, Díaz- Narváez VP, González-Cruz SA. Levels of empathy in dental students at Universidad San Sebastián in Concepción, Chile Rev Fac Med. 2017;65(2):219-25.[FullText]. 